\title{
FORMAÇÃO PARA A DOCÊNCIA NOS ANOS INICIAIS NA ALEMANHA
}

\author{
CATIA PICCOLO VIERO DEVECHI ${ }^{*}$ \\ ORCID: https://orcid.org/0000-0002-5147-1609 \\ WIVIAN WELLER ${ }^{1 * *}$ \\ ORCID: https://orcid.org/0000-0003-1450-2004
}

RESUMO: $O$ artigo apresenta os resultados de uma pesquisa sobre a reorganização dos cursos de formação para a docência nos anos iniciais no Estado da Renânia do Norte-Vestfália na Alemanha a partir das orientações de Bolonha e da implementação das normas educacionais sancionadas pela KMK em 2004. Analisa documentos normativos e as propostas curriculares atuais dos cursos de duas universidades (UDE e WWU) e dados produzidos por meio de entrevistas narrativas realizadas em 2017 com professores dos Institutos de Ciências da Educação e com coordenadores dos Centros de Formação Docente das mesmas universidades. Com base na análise dos dados, constatamos que os projetos pedagógicos dos cursos se organizam em conformidade com os documentos normativos do Estado NRW, com os acordos realizados em âmbito nacional e com as orientações do processo de Bolonha. O foco é preparar o futuro docente com as competências necessárias para o trabalho na escola primária. Tais propósitos orientadores, apesar de críticas recebidas, foram incorporados nos cursos de bacharelado e mestrado com o objetivo de formar profissionais crítico-reflexivos que correspondam às demandas do sistema educacional. Os cursos demonstram, claramente, os seus alicerces na profissionalização da área de ensino para a educação básica. Palavras-chave: Educação internacional e comparada; Currículo; Formação de professores; Docência nos anos iniciais; Universidades alemãs.

\section{TEACHER TRAINING PROGRAMS FOR PRIMARY SCHOOL IN GERMANY}

ABSTRACT: This article discusses the reorganization of teacher training programs for the elementary school after the Boulogne guidelines and the implementation of educational norms enacted by the KMK in 2004 in the German Federal State of North Rhine-Westphalia (NRW). It analyses documents and curricular proposals of two universities (UDE and WWU)

\footnotetext{
${ }^{1}$ Universidade de Brasília, Faculdade de Educação,Brasília, DF, Brasil.

"Doutora em Educação. Professora associada da Faculdade de Educação da Universidade de Brasília e coordenadora do GEFFOP. Grupo de estudos sobre filosofia da educação e formação de professores. E-mail:<catiaviero@gmail.com>.

" Doutora em Sociologia. Professora associada da Faculdade de Educação da Universidade de Brasília e coordenadora do GERAJU - Grupo de pesquisa gerações e juventude. E-mail:< wivian@unb.br > .
} 
as well as data produced in 2017 by narrative interviews with professors of the Institute of Educational Sciences and with coordinators of the Teacher Training Centers of both universities. Based on the data analysis, we found that the pedagogical projects of the courses are organized according to the Teacher Training Act of the NRW, with the national agreements of the Standing Conference of the Ministers of Education and Cultural Affairs and with the guidelines of the Boulogne process. The focus of the training programs is to prepare future teachers with the necessary competencies for the work in primary schools. Such guided proposals, despite the received critics, were incorporated in the bachelor and master courses. The curriculum clearly focuses on the professionalization and development of teaching abilities for primary education.

Keywords: International and comparative education; Curriculum; Teacher training; Teaching in the early years; German universities.

\section{INTRODUÇÃO}

Com as orientações do Processo de Bolonha, os países da Comunidade Europeia passaram a reestruturar os seus cursos universitários, com o objetivo, entre outros, de criar maior convergência da grade curricular no bacharelado e no mestrado, facilitar e incentivar a mobilidade acadêmica dos estudantes e o processo de internacionalização das universidades. Diante de inúmeras discussões sobre os rumos das universidades, foram definidas no âmbito do Parlamento e do Conselho Europeu, no ano de 2006, algumas recomendações sobre competências essenciais que pudessem responder os anseios da sociedade globalizada e do conhecimento, somada a um maior compromisso social e econômico na Europa. Nesse sentido, foram elencadas as seguintes competências essenciais para a aprendizagem ao longo da vida: comunicação na língua materna e em línguas estrangeiras; competência matemática; competências básicas em ciências e tecnologia; competência digital; aprender a aprender; competências sociais e cívicas; espírito de iniciativa e espírito empresarial; sensibilidade e expressão culturais. ${ }^{1}$ Além das competências essenciais, foram definidos alguns temas que deveriam fazer parte da formação para a docência nos anos iniciais, dentre os quais: pensamento crítico, criatividade, espírito de iniciativa, resolução de problemas, avaliação de riscos, tomadas de decisões e gestão construtiva de sentimentos. Dessa forma, foi consolidada a ideia de que o paradigma de ensino centrado na transmissão do conhecimento deveria ser substituído por um modelo de curso universitário orientado pelo desenvolvimento dessas competências essenciais. 
A partir do ano escolar 2005/2006 todos os 16 Estados da República Federal da Alemanha passaram a adotar - ainda que de forma distinta -, normas educacionais (Bildungsstandards) definidas em dezembro de 2004 pela Conferência Permanente de Ministros da Educação e Cultura (Kultusministerkonferenz - KMK). ${ }^{2}$ Apesar das críticas às normas educacionais acordadas pela KMK, sobretudo pela academia, cada Estado realizou a reforma de seu sistema educacional e instituiu as competências a serem adquiridas pelos alunos (cf. ZEITLER, HELLER; ASBRAND, 2012). De acordo com Terhardt $(2005,2014)$ a introdução dessas normas educacionais resultaram, por um lado, do estado de choque gerado na Alemanha a partir dos resultados das avaliações do Pisa nos anos 1990 e início dos anos 2000. Por outro, a pesquisa internacional sobre a profissão docente e a formação de docentes também reforçou a instituição de normas para docentes (Standards für die Lehrerbildung), especialmente em relação às competências a serem adquiridas durante a formação. Outros especialistas destacam que essas reformas não são nacionais e tampouco internacionais, mas inspiradas em contextos econômicos globais que são tomadas de empréstimo para impulsionar demandas locais com o apoio de organismos internacionais como a OCDE (cf. BLÖMEKE, 2006; CASALE et al., 2010, STEINER-KHAMSI, 2004).

Concomitante à reforma curricular nos anos iniciais e nas etapas escolares subsequentes, as universidades alemãs também tiveram que adequar seus cursos às novas diretrizes. Entre 2007 e 2016, praticamente todas as universidades realizaram a reforma curricular que introduziu os cursos universitários em dois ciclos: bacharelado - B.A. (6 a 7 semestres, dependendo da instituição) e mestrado - M.A. (2 a 4 semestres). Além do sistema sequencial entre bacharelado e mestrado, as universidades passaram a organizar os cursos por módulos e introduziram o sistema europeu de transferência de créditos (European Credit Transfer Systems - ECTS) com o objetivo de atender demandas de mobilidade acadêmica identificadas na comunidade europeia e apoiadas por programas como o Erasmus e Erasmus Mundus. Nesse sentido, as universidades tiveram que reestruturar os seus sistemas de ensino, buscando a cooperação internacional e uma orientação mais direcionada para as necessidades práticas das respectivas profissões.

Nesseartigo, discutimosareorganizaçãodos cursosde formação para a docência nos anos iniciais a partir das orientações de Bolonha e da implementação das normas educacionais (Bildungsstandards) sancionadas pela KMK em 2004. Considerando que em cada um dos 
16 estados da Alemanha existe uma legislação própria, ${ }^{3}$ selecionamos para esse estudo o Estado da Renânia do Norte-Vestfália (NordrheinWestfalen - NRW) e duas de suas universidades. A partir de uma abordagem comparativa e hermenêutica buscamos compreender como se deu a reorganização dos cursos de formação do docente para a escola primária a partir do Processo de Bolonha, tendo como base de dados a análise dos documentos normativos e das propostas curriculares dos cursos e de entrevistas narrativas com professores dos Institutos de Ciências da Educação e com coordenadores dos Centros de Formação Docente (Zentrum für Lehrerbildung - ZLB) das duas universidades que realizamos em fevereiro de 2017.

\section{A FORMACุÃO DOS DOCENTES DA ESCOLA PRIMÁRIA NO ESTADO DA RENÂNIA DO NORTÉVVESTFÁLIA - NRW}

No Estado da NRW todos os cursos de formação de docentes são universitários e se orientam pela Lei de Diretrizes da Formação Docente (Lehrerausbildungsgesetz - LABG) que entrou em vigor no dia 26 de maio de 2009, tendo a sua última revisão em 14 de junho de 2016, bem como pelo Decreto de Acesso ao Exercício da Docência (Lehramtszugangsverordnung - LZV), que foi atualizado, pela última vez, em 25 de abril de 2016. De acordo com a LABG e o LZV, os Estados e as universidades devem se comprometer com a formação dos docentes, levando em consideração os desafios educacionais e as necessidades das escolas nas suas diferentes especificidades. $\mathrm{Na}$ LABG, os objetivos da formação são assim definidos:

(1) Objetivo da formação é a capacitação para o exercício da docência em escolas públicas de forma autônoma. Os requisitos exigidos na formação do corpo docente para o exercício da profissão, são regidos pelo \102 da Lei Escolar do NRW.

(2) A formação é dividida em estudo e serviço preparatório. A formação inicial e continuada, incluindo o ingresso na profissão, se orienta pelo desenvolvimento de competências profissionais básicas para o ensino e a educabilidade (Eræįehung), avaliação, diagnóstico, orientação, cooperação e desenvolvimento escolar, bem como para as exigências científicas e artísticas das disciplinas. Nisso compreende-se a capacidade de lidar profissionalmente com a diversidade, sobretudo, com vistas a um sistema escolar inclusivo, bem como a capacidade de cooperação particularmente com os pares, com os pais, com outros grupos profissionais e outras instituições. A formação deve desenvolver a capacidade e fortalecer a disposição para o reconhecimento, incentivo e desenvolvimento das potencialidades e habilidades individuais de todos os alunos e alunas.

(3) O serviço escolar e a preparação para o serviço pressupõe o domínio da língua alemã, que possibilite o seu uso em sala de aula e no desempenho de todas as atividades de um docente. (LABG, 2016, art. $1^{\circ}$, \& 2). 
A LABG (2016) explicita que os cursos de formação devem preparar os docentes para exercer a profissão de forma autônoma. $\mathrm{O}$ termo capacidade (Befähigung) é citado quatro vezes no $\$ 2$, reforçando o argumento de o estudo nas duas fases (bacharelado e mestrado) deve promover o desenvolvimento de competências profissionais básicas para a prática docente na escola. Para tanto, a formação é dividida em estudo e preparação prática, sendo obrigação dos cursos universitários capacitar os futuros docentes para uma abordagem profissional voltada à diversidade e à heterogeneidade do público escolar, em particular a um sistema de educação inclusiva e cooperativa. É tarefa da formação permitir o reconhecimento das diferenças e desenvolvimento de qualificações necessárias para a identificação das potencialidades e habilidades individuais de todos os estudantes.

No que se refere aos cursos de formação de docentes para os anos iniciais ou para a escola primária (Grundschule), além do componente curricular obrigatório denominado Ciências da Formação (Bildungswissenschaften), ${ }^{4}$ a LABG (art. 3o, \11; 6.1) definiu como parte obrigatória os estudos relacionados às áreas "formação básica em linguística e formação básica em matemática, bem como uma outra área de aprendizagem ou disciplina escolar, acrescido das didáticas específicas". Os estágios também foram definidos como componentes da formação durante o curso, apresentando as seguintes características: (1) um estágio de aptidão e orientação com duração mínima de 25 dias durante um semestre escolar, a ser absolvido preferencialmente em cinco semanas consecutivas; (2) um estágio vocacional (Berufsfeldpraktikum) com duração mínima de quatro semanas, a ser realizado preferencialmente em espaços não escolares; (3) um semestre prático com duração de pelo menos cinco meses, que paralelo às aulas na universidade deve compreender pelo menos a metade da carga horária ministrada nas escolas (idem, art. 3o, \12;1). A carga horária dos cursos e créditos a serem cursados em cada área de estudo é regulamentada pelo LZV, apresentando a seguinte distribuição (LZV, 2016, \4):

- Área I - Formação básica em letras / língua materna (55 LP); ${ }^{5}$

- Área II - Formação básica em matemática (55 LP);

- Área III - Formação em outra área do conhecimento ou outra disciplina, acrescido das didáticas específicas (55 LP);

- Aprofundamento nas áreas I, II ou III ou em uma disciplina escolar (12 LP);

- Ciências da formação / Bildungswissenschaften (64 LP); 
- Alemão para alunos e alunas com histórico familiar de migração (6 LP);

- Semestre prático (25 LP);

- Trabalho de conclusão de curso de bacharelado e mestrado (28 LP).

A carga horária total dos cursos é bastante extensa, mesclando uma formação por meio de estágios, cursos de leitura (Vorlesung), aulas expositivas, seminários, aulas online e estudos individuais, o que atende a perspectiva de desenvolvimento das normas educacionais (cf. KMK, 2004). São cerca de 9.000 horas previstas entre mestrado e bacharelado, mais 18 meses de residência escolar (Referendariat) depois da conclusão do mestrado e, por último, a realização do exame de Estado (Staatsprüfung) que habilita o ingresso na carreira. A carga horária entre as áreas de estudo I, II e III, o componente Ciências da Formação, os estágios e trabalho final de curso em nível de bacharelado e mestrado são distribuídos de forma equilibrada. Tal distribuição de créditos indica a preocupação tanto com a formação em conteúdos específicos a serem aprendidos, como com a experiência prática e com as Ciências da Formação.

$\mathrm{Na}$ área de estudo III, de livre escolha dos estudantes, são oferecidas as seguintes possibilidades de acordo com o $\int 4$ da LZV: a) estudo de ciências naturais e sociais (Sachunterricht) ou educação estética (Ästhetische Er:iehung); b) estudo de uma disciplina específica, dentre as quais: inglês, ensino da religião evangélica/luterana, ensino da religião islâmica, ensino da religião católica, artes música, ou esporte; c) Aprofundamento no ensino do alemão para alunos e alunas com histórico familiar de migração com possibilidade de integralização de créditos por meio do estudo de uma língua de origem da população com antecedentes migratórios. Os temas e conteúdos a serem trabalhados nas áreas de estudo I, II e III nos respectivos cursos universitários não são detalhados na LZV. Já em relação ao componente Ciências da Formação, que compreende a maior carga horária dos cursos (64 LP ou cerca de $22 \%$ da formação), a LABG define que os estudos se concentrem na aprendizagem precoce, incluindo aspectos centrais da pedagogia dos anos elementares e da pedagogia do desenvolvimento" (LABG, \11, 6.1). A LZV, por sua vez, detalha em seu $\ 2$ os conteúdos a serem contemplados neste componente, a saber: Ciências da Formação incluindo a pedagogia dos anos iniciais; elementos da práxis; conceitos da aprendizagem 
precoce e conceitos da formação e educação pré-escolar; diagnóstico e incentivo/estímulo (como parte integrante das didáticas específicas); questões/temas relacionados à inclusão; produções relacionadas a questões específicas da inclusão de alunos e alunas com necessidade de atendimento pedagógico especial.

De uma forma geral, observa-se que a formação para a docência nas escolas primárias do Estado NRW, tal como determinado na LABG e no LZV, se orienta pelo princípio acordado em 2004 no âmbito do Parlamento e do Conselho da União Europeia, apresentando uma forte preocupação com a profissionalização do docente, com a significação da teoria e da prática pedagógica, com a inserção social e inclusão dos alunos com histórico familiar de migração. Está orientada para o desenvolvimento das competências para o ensino e aprendizagem da língua materna, da matemática, das ciências naturais e sociais, da língua estrangeira (inglês), artes, música, esportes bem como da capacidade de avaliar, diagnosticar e orientar alunos e alunas com suas diferenças. Além disso, percebe-se uma grande preocupação com o conhecimento, com a postura reflexiva sobre a escola, com a qualidade da profissionalização e aptidão dos docentes para o trabalho colaborativo. Entretanto, nos perguntamos: como os cursos passaram a se organizar a partir das novas orientações legais? Buscaremos responder essa questão a partir do estudo da organização do curso em duas universidades do Estado NRW.

\section{A FORMAC̦ÃO DOS DOCENTES NA UNIVERSIDADE DE MÜNSTER E NA UNIVERSIDADE DE DUISBURG-ESSEN}

Os cursos de formação na Westfälische Wilhelms-Universität Münster (WWU-Münster) e na Universität Duisburg-Essen (UDE) atendem as exigências da LABG (2009 e 2016) e do LZV (2016) no que diz respeito à estrutura curricular para o bacharelado e mestrado. Os cursos formam bacharéis para a docência na escola primária com a seguinte titulação: Bachelor of Science Lebramt an Grundschulen. No entanto, para atuar como docente nos anos iniciais, o estudante deve continuar os seus estudos em nível de mestrado. O currículo dos cursos nas duas universidades está organizado da seguinte forma: 
QUADRO 1. Universität Münster - WWU

\begin{tabular}{|c|c|c|c|c|c|}
\hline \multirow[b]{2}{*}{$\begin{array}{c}\text { Mestrado } \\
4 \\
\text { semestres }\end{array}$} & \multicolumn{3}{|c|}{$\begin{array}{l}\text { Aprofundamento em uma das áreas ou disciplina } \\
\qquad 12 \mathrm{LP}\end{array}$} & \multirow{2}{*}{$\begin{array}{c}\text { Ciências } \\
\text { da Formação } \\
20 \mathrm{LP} \\
\text { Semestre } \\
\text { prático } \\
25 \mathrm{LP}\end{array}$} & \multirow[b]{2}{*}{$\begin{array}{l}\text { Dissertação } \\
18 \mathrm{LP}\end{array}$} \\
\hline & $\begin{array}{c}\text { Área } 1 \\
\text { Formação } \\
\text { Básica em } \\
\text { Letras } \\
\text { 13LP } \\
\text { (obrigatória) }\end{array}$ & $\begin{array}{c}\text { Área } 2 \\
\text { Formação } \\
\text { Básica em } \\
\text { Matemática } \\
\text { 13LP } \\
\text { (obrigatória) }\end{array}$ & $\begin{array}{c}\text { Área } 3 \\
\text { 13LP } \\
\text { (livre escolha) }\end{array}$ & & \\
\hline $\begin{array}{c}\text { Bacharelado } \\
6 \\
\text { semestres }\end{array}$ & $\begin{array}{l}\text { Área } 1 \\
\text { Formação } \\
\text { Básica em } \\
\text { Letras } \\
\text { 42LP } \\
\text { (obrigatória) }\end{array}$ & $\begin{array}{c}\text { Área } 2 \\
\text { Formação } \\
\text { Básica em } \\
\text { Matemática } \\
\text { 42LP } \\
\text { (obrigatória) }\end{array}$ & $\begin{array}{c}\text { Área } 3 \\
\text { 42LP } \\
\text { (livre escolha) }\end{array}$ & $\begin{array}{c}\text { Ciências } \\
\text { da Formação } \\
\text { 44LP } \\
\text { Estágio } \\
\text { vocacional } \\
\text { Estágio de } \\
\text { aptidão e } \\
\text { orientação }\end{array}$ & $\begin{array}{l}\text { TCC } \\
10 \mathrm{LP}\end{array}$ \\
\hline
\end{tabular}

Fonte: Quadro traduzido e adaptado a partir de: < https:/|www.uni-muenster.de/Lehrerbildung/lehramtsstudium/bachelor/ grundschule.html > . Acesso em: 17 abr. 2017

QUADRO 2. Universität Duisburg-Essen - UDE

\begin{tabular}{|c|c|c|c|c|c|}
\hline \multirow[b]{2}{*}{$\begin{array}{c}\text { Mestrado } \\
4 \\
\text { semestres }\end{array}$} & \multicolumn{3}{|c|}{$\begin{array}{l}\text { Aprofundamento em uma das áreas ou disciplina } \\
\qquad 12 \mathrm{LP}\end{array}$} & $\begin{array}{l}\text { Ciências da } \\
\text { Formação } \\
\text { 18LP } \\
\text { Semestre } \\
\text { prático } \\
\text { 25LP }\end{array}$ & \multirow[b]{2}{*}{$\begin{array}{l}\text { Dissertação } \\
20 \mathrm{P}\end{array}$} \\
\hline & $\begin{array}{c}\text { Área } 1 \\
\text { Formação } \\
\text { Básica em } \\
\text { Letras } \\
\text { 13LP } \\
\text { (obrigatória) }\end{array}$ & $\begin{array}{c}\text { Área } 2 \\
\text { Formação } \\
\text { Básica em } \\
\text { Matemática } \\
\text { 13LP } \\
\text { (obrigatória) }\end{array}$ & $\begin{array}{c}\text { Área } 3 \\
\text { 13LP } \\
\text { (livre escolha) }\end{array}$ & $\begin{array}{c}\text { Semestre } \\
\text { prático } \\
25 \mathrm{LP} \\
\text { Alemão } \\
2^{\mathrm{a}} \text { língua } \\
6 \mathrm{LP}\end{array}$ & \\
\hline $\begin{array}{c}\text { Bacharelado } \\
6 \\
\text { semestres }\end{array}$ & $\begin{array}{c}\text { Área } 1 \\
\text { Formação } \\
\text { Básica em } \\
\text { Letras } \\
\text { 41LP } \\
\text { (obrigatória) }\end{array}$ & $\begin{array}{c}\text { Área } 2 \\
\text { Formação } \\
\text { Básica em } \\
\text { Matemática } \\
\text { 41LP } \\
\text { (obrigatória) }\end{array}$ & $\begin{array}{c}\text { Área } 3 \\
\text { 41LP } \\
\text { (livre escolha) }\end{array}$ & $\begin{array}{l}\text { Ciências da } \\
\text { Formação } \\
\text { 37LP } \\
\text { Estágio } \\
\text { vocacional } \\
6 \mathrm{LP} \\
\text { Estágio de } \\
\text { aptidão e } \\
\text { orientação } \\
\text { lemão 2a língua } \\
6 \mathrm{LP}\end{array}$ & \\
\hline
\end{tabular}

Fonte: Quadro traduzido e adaptado a partir das informações disponíveis em $<$ https://www.uni-due.de/de/studium/ $>$. Acesso em: 17 abr. 2017. 
Existem poucas diferenças na estrutura curricular dos cursos de formação para a docência nos anos iniciais entre as duas universidades. Os estudantes precisam assistir às aulas e participar de atividades relacionas à formação básica em letras - que compreende o estudo da língua materna (alemão) -, à formação básica em matemática e à uma terceira área de estudo (ciências naturais e sociais) ou disciplina específica do currículo escolar para os anos iniciais. Assim, é permitido ao estudante selecionar uma área ou disciplina de seu interesse, conforme previsto no LZV. Dessa forma, o futuro docente da escola primária estará sempre atuando com outros colegas em uma classe escolar. As disciplinas e demais atividades das áreas de estudo obrigatórias bem como da área de livre escolha, são cursadas nos respectivos departamentos ou institutos, sendo que os futuros docentes também realizam atividades com estudantes das licenciaturas para as escolas de nível secundário. Por exemplo: na universidade de Münster, a formação básica em matemática para os anos iniciais ocorre no Departamento de Matemática e Informática (FB10) e a formação em letras/língua materna no Departamento de Filologia (FB09). O mesmo ocorre na universidade Duisburg-Essen. Os Institutos de Ciências da Educação da UDE e da WWU - além da oferta de outros cursos de bacharelado e de mestrado -, são responsáveis, em conjunto com os Institutos de Psicologia, apenas pela oferta do componente Ciências da Formação e pela disciplina alemão como segunda língua para todos os estudantes dos cursos de formação docente, o que corresponde a cerca de $22 \%$ das atividades previstas na estrutura curricular do curso voltado para a docência nas escolas primárias.

\section{O COMPONENTE CIÊNCIAS DA FORMAC̣ÃO NA FORMAC̣ÃO DOS DOCENTES}

Como já mencionado anteriormente, os conteúdos ou temas gerais a serem trabalhados no componente Ciências da Formação estão definidos na LABG e no LZV, de forma que os institutos responsáveis pela organização dos módulos precisam orientar-se por este documento na organização das atividades. Apesar das discussões em torno da introdução dos Bildungsstandards nos cursos de formação docente, a forma como se deu a articulação de diferentes áreas sob a denominação Bildungwissenschaften, foi e ainda continua sendo alvo de muitas críticas, uma vez que no modelo atual as Ciências da Educação encontram-se inseridas em uma estrutura hierárquica distinta, que diminuiu o campo de atuação da pedagogia enquanto "teoria reflexiva da prática pedagógica" (RADTKE, 2016, p. 711) e enquanto espaço de "profissionalização da ação pedagógica dos docentes" (CASALE 
et al. 2010). Ao mesmo tempo, outros autores defendem que essa nova denominação e a inserção de conhecimentos que mantêm maior relação com o futuro campo de atuação dos docentes conferiu maior dignidade científica a este componente curricular (TERHARDT, 2012), já que até então, tal área não tinha alcançado o seu devido reconhecimento nos cursos de formação docente.

$\mathrm{Na}$ universidade de Münster o componente Ciências da Formação é ministrado no bacharelado e no mestrado sobretudo pelo Instituto de Ciências da Educação (vinculado ao FB06) e pelo Instituto de Psicologia na Formação e na Educação (FB07). Há ainda a participação do Instituto de Sociologia (FB06) com um módulo obrigatório no bacharelado e do Instituto de Filosofia (FB08) com um módulo optativo no mestrado. Em relação ao estudo das Ciências da Formação o curso oferece no bacharelado seis módulos obrigatórios com um total de 44 créditos (1320 horas). No mestrado são oferecidos dois módulos obrigatórios e cinco optativos (dentre os quais os estudantes precisam escolher um), totalizando 20 créditos (600 horas). Tais são os módulos: 
QUADRO 3. Módulos em Ciências da Formação - Universidade de Münster

\begin{tabular}{|c|c|c|c|c|}
\hline \multirow{4}{*}{$\begin{array}{c}\text { Mestrado } \\
4 \\
\text { semestres }\end{array}$} & Módulos & $\begin{array}{l}\text { Instituto } \\
\text { responsável }\end{array}$ & Semestre & $\begin{array}{l}\text { Créditos } \\
1 \mathrm{créd} . \\
=30 \mathrm{~h}\end{array}$ \\
\hline & $\begin{array}{l}\text { Módulo de livre escolha dentre as seguintes } \\
\text { opções: } \\
\text { ELS - Processos de desenvolvimento, } \\
\text { aprendizagem e socialização } \\
\text { LES-FA - Aprendizagem, desenvolvimento } \\
\text { e processos sociais: pesquisa e aplicação } \\
\text { TEB - Teoria e história da educação } \\
\text { e da formação } \\
\text { FOL - Pesquisa na aprendizagem } \\
\text { PHE - Filosofia elementar }\end{array}$ & $\begin{array}{l}\text { Educação } \\
\text { Psicologia } \\
\text { Educaçãa } \\
\text { Educação } \\
\text { Filosofia }\end{array}$ & -. & 6 \\
\hline & $\begin{array}{l}\text { SOP - Educação Especial / Sonderpädagogik } \\
\text { (obrigatório) }\end{array}$ & Educação & -. & 7 \\
\hline & $\begin{array}{l}\text { ULI - Ensino em sala de aula como processo de } \\
\text { aprendizagem, ensino e interação (obrigatório) }\end{array}$ & Educação & .. & 7 \\
\hline \multirow{6}{*}{$\begin{array}{c}\text { Bacharelado } \\
6 \\
\text { semestres }\end{array}$} & EB - Educação primária (Elementarbildung) & Educação & -. & 10 \\
\hline & BFP - Estágio vocacional (Berufsfeldpraktikum) & $\begin{array}{l}\text { Educação/ } \\
\text { outros }\end{array}$ & .. & 7 \\
\hline & $\begin{array}{l}\text { LESD - Aprendizagem, desenvolvimento, } \\
\text { processos sociais e diagnósticos }\end{array}$ & Psicologia & -. & 7 \\
\hline & $\begin{array}{l}\text { BWG - Processos de formação } \\
\text { e mudança social }\end{array}$ & Sociologia & $\cdot-$ & 7 \\
\hline & BFP - Estágio de orientação & Educação & -. & 6 \\
\hline & $\begin{array}{l}\text { EBS - Introdução às questões básicas } \\
\text { da educação, da formação e da escola }\end{array}$ & Educação & $\cdots$ & 7 \\
\hline
\end{tabular}

Fonte: Elaboração do quadro pelas autoras a partir das informações constantes em: http://www.uni-muenster.de/ Bildungswissenschaften/studium/index.html. Acesso em: 17 jul. 2017. 
A Universidade de Duisburg-Essen está organizada em faculdades, sendo uma delas a faculdade de Ciências da Formação, que entre outras funções, é responsável pelo componente Bildungwissenschaften na formação dos futuros docentes para todos os níveis escolares e modalidades. Criada no ano de 2004 a partir da fusão que ocorreu entre as universidades de Duisburg e Essen, é hoje uma das maiores faculdades de Ciências da Formação da Alemanha com cerca de 50 professores catedráticos, aos quais estão vinculados pesquisadores/docentes e outros funcionários. A faculdade compreende os seguintes institutos: Instituto de Formação Profissional e Continuada, Instituto de Ciências da Educação, Instituto de Psicologia, Instituto de Serviço Social e Políticas Sociais, Instituto de Desenvolvimento Regional, Trabalho Comunitário Social e Aconselhamento (ISSAB), Instituto de Desporto e Ciências Físicas.

No componente Ciências da Formação, os estudantes do bacharelado e do mestrado recebem formação, prioritariamente, no campo das Ciências da Educação, Psicologia Escolar, Psicologia do Desenvolvimento e Sociologia da Educação. O objetivo é oferecer ao estudante um saber profissional fundado cientificamente, orientado ao campo da ação pedagógica, que o permita identificar questões e problemas pedagógicos relacionados à prática escolar. O componente Ciências da Formação está organizado por módulos, conforme apresentado no quadro 04. 
QUADRO 4. Módulos em Ciências da Formação - Universidade Duisburg-Essen

\begin{tabular}{|c|c|c|c|c|}
\hline \multirow{6}{*}{$\begin{array}{l}\text { Mestrado } \\
\quad 4 \\
\text { semestres }\end{array}$} & Módulos & $\begin{array}{l}\text { Instituto } \\
\text { responsável }\end{array}$ & Semestre & $\begin{array}{l}\text { Créditos } \\
1 \text { créd. } \\
=30 \mathrm{~h}\end{array}$ \\
\hline & $\begin{array}{l}\text { PHW - Desenvolvimento Científico } \\
\text { das Ações Profissionais } \\
\text { (Perspectivas das áreas de ensino; } \\
\text { Perspectivas das Ciências da Formação) }\end{array}$ & $\begin{array}{c}\text { Educação e } \\
\text { Psicologia }\end{array}$ & $4^{0}$ & 9 \\
\hline & $\begin{array}{l}\text { MC - Pesquisa na Formação } \\
\text { (Estrutura, avaliação e desenvolvimento do } \\
\text { sistema educacional alemão; Avaliação e } \\
\text { desenvolvimento escolar; Conduta profissional } \\
\text { nas demandas e encargos escolares) }\end{array}$ & Educação & $3^{0}$ & 7 \\
\hline & $\begin{array}{l}\text { PS - Semestre Prático } \\
\text { (Oficina de pesquisa: acompanhamento do } \\
\text { estágio semestral; Eventos/seminários de } \\
\text { acompanhamento nas áreas de estudo) }\end{array}$ & $\begin{array}{l}\text { Educação e } \\
\text { Psicologia }\end{array}$ & $2^{0}$ & 25 \\
\hline & $\begin{array}{l}\text { MB - Oficina de Pesquisa em } \\
\text { Ciências da Formação } \\
\text { (Oficina de pesquisa: preparação para o estágio } \\
\text { semestral; Estudos independentes: adaptação } \\
\text { ao projeto de pesquisa) }\end{array}$ & $\begin{array}{c}\text { Educação e } \\
\text { Psicologia }\end{array}$ & $1^{0}+2^{0}$ & 5 \\
\hline & $\begin{array}{l}\text { MA - Escola e Ensino (Unterricht) } \\
\text { (Pedagogia dos anos iniciais; Gestão } \\
\text { da classe escolar) }\end{array}$ & $\begin{array}{l}\text { Educação e } \\
\text { Psicologia }\end{array}$ & $1^{0}$ & 4 \\
\hline \multirow{4}{*}{$\begin{array}{l}\text { Bacharelado } \\
6 \\
\text { semestres }\end{array}$} & $\begin{array}{l}\text { IV - Condições Heterogêneas } \\
\text { do Crescimento } \\
\text { (Heterogeneidade, socialização e inclusão; } \\
\text { seminários de projetos de pesquisa; } \\
\text { Infância, escola e apoio à crianças } \\
\text { e jovens; colóquio modular) }\end{array}$ & $\begin{array}{c}\text { Educação e } \\
\text { Psicologia }\end{array}$ & $5^{0} \mathrm{e} 6^{0}$ & 13 \\
\hline & $\begin{array}{l}\text { III - Educação, Formação e Docência } \\
\text { (Tópicos básicos da pedagogia geral; didática } \\
\text { geral; educação, formação e ensino) }\end{array}$ & Educação & $4^{0}$ & 6 \\
\hline & $\begin{array}{l}\text { II - Psicologia } \\
\text { (Introdução à psicologia do ensino e } \\
\text { aprendizagem; Psicologia pedagógica/escolar, } \\
\text { diagnóstico e inclusão; } \\
\text { Psicologia do desenvolvimento) }\end{array}$ & Psicologia & $3^{0}$ & 6 \\
\hline & $\begin{array}{l}\text { I- Profissionalização Pedagógica } \\
\text { (Profissionalização pedagógica nos espaços de } \\
\text { ação pedagógica; Trabalho científico em ciências } \\
\text { da educação; Seminários de preparação prévia e } \\
\text { posterior aos estágios de aptidão e orientação) }\end{array}$ & Educação & $1^{\circ}$ e $2^{0}$ & 12 \\
\hline
\end{tabular}

Fonte: Quadro elaborado pelas autoras, traduzido e adaptado a partir do Manual do Bacharelado e Manual do Mestrado para a docência na escola primária. 
No que diz respeito aos conteúdos dos módulos relacionados às Ciências da Educação, em ambas as universidades ${ }^{6}$ são trabalhadas teorias pedagógicas, questões voltadas para a escola, ensino e aprendizagem e a formação profissional. O propósito é orientar os estudantes no estudo da escola, em relação às exigências do trabalho científico na área, apresentá-los a uma introdução sobre as teorias históricas e atuais sobre formação e educação, discutir a formação de crianças de 0 a 10 anos (do nascimento até final dos anos iniciais). O estudo busca oportunizar a aplicação e experimentação das teorias no contexto prático-investigativo de forma crítica e reflexiva. Nas duas instituições, o primeiro estágio é realizado com orientação de professores das Ciências da Educação. São trabalhados também conceitos da didática geral, modelos e resultados da pesquisa empírica sobre ensino em sala de aula, planejamento do processo de ensino, aprendizagem e interação, avaliação dos resultados da própria atividade profissional (planejamento do ensino em sala de aula). Questões de desenvolvimento na aprendizagem e avaliação do rendimento, resolução de conflitos em sala de aula. Estudam teoria e história da formação e suas instituições, desenvolvimento histórico cultural de infância, juventude e relações entre gerações, história do sistema educacional e da política da formação, problemas e tarefas da historiografia pedagógica, assim como as conexões e as diferenças entre formação, ciência e crítica. Tais discussões são apresentadas de forma introdutória no bacharelado e aprofundadas no mestrado.

Em relação aos estudos de Psicologia, percebe-se um enfoque no diagnóstico das habilidades e competências, nos processos de desenvolvimento e de aprendizagem na infância. São oferecidos aos estudantes: conhecimentos sobre teorias, métodos e resultados de pesquisa para a descrição, explicação, previsão e incentivo/apoio de processos individuais de aprendizagem e de desenvolvimento de alunas e alunos; a possibilidade de avaliação de materiais e métodos de ensino a partir de modelos e teorias psicológicas; a aquisição de saberes teóricos e aplicados relativos às abordagens psicológicas que tratam da diversidade na aprendizagem e no rendimento; a capacidade de analisar, avaliar e estruturar contextos de ensino e aprendizagem, considerando teorias e modelos da psicologia da aprendizagem e do desenvolvimento; condições de acompanhamento, incentivo e avaliação individual das aprendizagens.

O componente Ciências da Formação também compreende estudos sobre questões sociais, com ênfase na Sociologia da Educação. ${ }^{7}$ Busca-se permitir que o estudante compreenda como 
as transformações sociais influenciam na educação, tendo em vista as funções do sistema educacional nesse contexto. Devem aprender a analisar os elementos socioestruturais que determinam as desigualdades de gênero, sociais e étnicas e as influências na aquisição de competências e nos processos educacionais. O propósito é que os estudantes adquiriram competências interpessoais e culturais, refletindo criticamente sobre as condições sociais e sociopolíticas que permeiam a educação. Os futuros docentes devem ser capazes de identificar mudanças em cada sistema social, avaliar as condições subjacentes e as suas consequências. Os projetos dos cursos apontam para um compromisso com as questões sociais, principalmente, no sentido de oferecer conhecimentos sobre a relação entre questão sociais e o desenvolvimento das crianças e jovens nos diversos níveis do sistema educacional, considerando ainda as condições heterogêneas e as desigualdades entre os estudantes.

Em função da elevada taxa de crianças e jovens com histórico familiar de migração que frequentam as escolas alemãs, ambas universidades estão focadas na questão da inclusão e do reconhecimento da heterogeneidade. $\mathrm{Na}$ universidade de Münster, os estudantes devem realizar um módulo obrigatório de educação especial onde é apresentada uma introdução das teorias e das abordagens fundamentais da pedagogia integrativa e inclusiva. Além disso, são tratadas algumas perspectivas de intervenção pedagógica especial, do apoio nas turmas de ensino primário inclusiva e de como lidar com a heterogeneidade. $\mathrm{Na}$ universidade de DuisburgEssen, é ofertado o módulo obrigatório "Condições heterogêneas do crescimento" que discute questões sobre a heterogeneidade, socialização, inclusão, escola, assistência às crianças e aos jovens. Um módulo optativo de Filosofia da Educação é ofertado apenas na Universidade de Münster, onde são trabalhadas as abordagens filosóficas e seus conceitos com o objetivo de ampliar as competências dos estudantes nas Ciências da Formação. Estudam também como tornar acessíveis estruturas e argumentos filosóficos no sentido de desenvolver uma competência analítica.

\section{ESTÁGIOS CURRICULARES E A ATRIBUIÇÃO DOS CENTROS DE FORMAC̣ÃO DOCENTE}

Como já apontado nos quadros 1 e 2, os estudantes devem realizar dois estágios no bacharelado. O estágio de orientação objetiva propiciar uma discussão crítica-analítica da prática escolar, a reflexão da aptidão para a profissão docente e para o desenvolvimento de uma perspectiva orientada para profissão em estudos posteriores. Busca 
apresentar ao estudante a complexidade do campo da ação na escola a partir de uma perspectiva profissional, estabelecendo as primeiras relações entre abordagens teóricas das Ciências da Formação e situações pedagógicas concretas. Possibilita ao estudante a reflexão sobre os campos de aprendizagens e práticas relativos à escola, as próprias possibilidades de ação no campo pedagógico, bem como a reflexão da escolha da profissão. O estágio vocacional é realizado em espaços educativos não-escolares, podendo ser realizado também no exterior. Tal estágio oferece aos estudantes oportunidades de carreira mais concretas fora da profissão docente, permitindo também percepções relevantes para a profissão docente.

Durante o mestrado os estudantes realizam um estágio prático para o qual são preparados por meio de seminários oferecidos na universidade. Durante o semestre do estágio, os conhecimentos e capacidades adquiridas no curso - relativos às áreas I, II e III, à didática das disciplinas específicas e às Ciências da Formação -, devem ser complementados e relacionados aos objetivos e às competências relativos à atuação na escola. Não se trata de ensinar a rotina da atividade de ensino. Trata-se, sobretudo, de iniciar e acompanhar o processo do "aprender pesquisando", em um contexto de elaboração individual e crítico-construtiva das relações entre as perspectivas teóricas e o que acontece na prática. A ideia é que o estudante possa questionar a teoria a partir da prática, e questionar a prática a partir da teoria, além de desenvolver um perfil profissional próprio. O estudante é incentivado a refletir sobre suas ações, realizar pesquisas, dialogar, documentar, comunicar e compartilhar seus conhecimentos. Além disso, aprendem os pressupostos básicos para planejar e ministrar aulas de forma autônoma no estágio subsequente (durante a residência) e para elaborar os focos temáticos da disciplina.

Após a conclusão do mestrado é necessário realizar o estágio profissional preparatório com duração de 18 meses (Referendariat). Essa fase é administrada pelo Estado que coordena e avalia as condições de admissão (pessoal, espacial, estrutural, orçamento) e oferece uma remuneração. Para adquirir a qualificação para o ingresso na carreira, além do estágio profissional, é necessário realizar o exame do Estado (Staatsprüfung). O Ministério da Educação do Estado, em conjunto com o Ministério do Interior e do Ministério das Finanças, elabora, regulamenta e autoriza a realização do exame. No certificado do exame ficam registrados o tipo de escola e as disciplinas nas quais o estudante se especializou. Somente após o exame de estado, o docente estará apto a pleitear uma vaga para trabalhar em uma escola. 
Os estágios são realizados em cooperação com as escolas e com os Centros de Formação Docente (Zentrum für Lehrerbildung - ZLB), que estão localizados nas universidades. Os ZLBs recebem suporte financeiro dos Ministérios de Educação dos Estados e se constituem como unidades independentes nas universidades, responsáveis, sobretudo, pelo incentivo interdisciplinar/transdisciplinar da formação acadêmica dos futuros docentes. Oferecem informações sobre os cursos, serviço de aconselhamento aos estudantes, suporte à coordenação dos cursos nas fases práticas (estágios), assim como na pesquisa, aplicação de saberes e aperfeiçoamento profissional. Os ZLBs foram criados com o objetivo de oferecer apoio à formação nas Ciências da Educação, nas disciplinas que serão ensinadas nas escolas, nas didáticas específicas e nas avaliações. Além disso, os ZLBs atuam na mediação entre a universidade, as escolas e os respectivos órgãos públicos bem como no estabelecimento de redes e canais de comunicação com as escolas. ${ }^{8}$

\section{PERCEPC̣ÃO DOS PROFESSORES EM RELAÇÃO ÀS MUDANC̣AS APÓS O PROCESSO DE BOLONHA E À IMPLEMENTAC̣̃̃O DOS BILDUNGSSTANDARDS}

Nessa seção do artigo, trataremos da percepção dos professores em relação às mudanças relativas à carga horária, ao componente Ciências da Formação e à autonomia na organização dos cursos pelas universidades. Para tanto, são analisados dados oriundos de quatro entrevistas narrativas com especialistas (cf. WELLER; ZARDO, 2013) realizadas pelas autoras no mês de fevereiro de 2017. As entrevistas foram realizadas com coordenadores dos Centros de Formação Docente (ZLB) e professores do Instituto de Educação da WWU e do Instituto de Pedagogia da EDU, com um total de seis participantes já que em uma das universidades as entrevistas ocorreram em dupla por opção dos professores que haviam sido previamente contatados. Em relação aos professores dos institutos, todos possuem formação inicial em Ciências Humanas. Entre os três entrevistados dos ZLBs, as formações iniciais foram em docência para as disciplinas de Matemática, Ciências Sociais/Inglês e Ciências Políticas. Caracterizaremos as entrevistas e respectivos entrevistados da seguinte forma: a letra "E" identifica as entrevistadoras, "B" os entrevistados das Ciências da Formação e a letra " $Z$ " os entrevistados dos ZLBs; os números cardinais que seguem $(1,2)$ identificam o número da entrevista; as letras em minúsculo (f, m) informam o sexo dos entrevistados. Nas entrevistas de pares acrescentamos um número 
ordinal após a identificação do sexo que corresponde a entrevistado I e entrevistado II. Para a realização da entrevistas, realizamos um roteiro prévio com dez questões que tratam, principalmente, sobre a adaptação dos cursos em relação as orientações do processo de Bolonha e da LABG, sobre os espaços de autonomia dos cursos e sobre o surgimento da área de Ciências da Formação. As entrevistas tiveram duração média de uma hora e trinta minutos cada, somando aproximadamente 6 horas de gravação. O objetivo das entrevistas foi compreender a percepção dos professores / coordenadores envolvidos com a formação docente para os anos iniciais acerca da reorganização dos cursos após o Processo de Bolonha e à implementação dos Bildungsstandards.

\section{ORGANIZAÇÃO E ESTRUTURA DOS CURSOS}

Uma mudança central na formação para a docência nos anos iniciais na Alemanha a partir do processo de Bolonha foi a ampliação dos anos de estudo e equiparação à formação de docentes para os níveis subsequentes no que diz respeito ao tempo de estudo e titulação, exigindo-se a realização do bacharelado e do mestrado, conforme apontado por B2f:

Ef: Como a senhora avalia essa classificação em bacharelado e mestrado agora especialmente para os estudantes das profissões docentes [Lehramt]; a senhora acha que há aspectos mais positivos ou mais negativos o que é melhor ou pior nessa divisão?

B2f: [...] é preciso dizer que especificamente para a docência nas escolas primárias essa reforma trouxe também muitas coisas positivas mas isso também foi discutido de forma controversa porque antes nós tínhamos a formação de professores da escola primária que era apenas seis semestres ou seja tão longa como um bacharelado e agora temos cinco anos né, dez semestres // Ef: $\operatorname{sim} / /$ e nós tínhamos claramente uma hierarquização das diversas profissões docentes, aqueles que se interessavam pelo liceu [Gymnasium] e pela escola integral [Gesamtschule] ou pela escola básica [Hauptschule] tinham um estudo de nove semestres e as futuras professoras e professores da escola primária tinham um estudo de sete semestres e isso teve realmente um efeito na profissionalização das professoras e professores da escola primária [...] essa equivalência dessas licenciaturas que veio através disso e esse foi um efeito positivo [...] 
A formação do docente para a escola primária passou a ser tratada com maior grau de profissionalização e organizada como nos demais cursos de formação de docentes para as escolas secundárias que já acontecia em nove ou dez semestres. ${ }^{9}$ Outro entrevistado destacou que a ampliação dos anos de estudo para a docência nos anos iniciais como um avanço que contribuiu para a eliminação de uma distinção que existia há séculos. Essa equivalência, segundo o entrevistado, não está relacionada somente ao aumento da carga horária do curso, mas ao reconhecimento de que "o trabalho nas escolas primárias também necessita de uma formação científica mais ampla e isso foi um progresso" (B1m).

Com duração de dez semestres a formação dos docentes está organizada em torno de quatro componentes: 1) Conteúdos nas áreas de conhecimento/disciplinas; 2) Didática dos conteúdos nas áreas de conhecimento/disciplinas; 3) Ciências da Formação e 4) Prática escolar (estágios). Contudo, o peso em termos de carga horária dado aos quatro elementos é distinto, conforme detalhado por um dos entrevistados:

B1m: [...] estes quatros componentes sempre estão presentes, conteúdo da disciplina didática da disciplina ciências da formação estágio, e agora é importante ver como estão distribuídos, isso é diferente nos cursos de formação de docentes. No curso para professores primários para o ensino na escola primária a parte pedagógica é relativamente alta perfazendo cerca de $20 \%$. nos cursos de docência para o liceu é menos, entre 10 e 15\%. isto também é diferente entre os Estados e em alguns Estados na formação de professores para o liceu a parte pedagógica é de apenas $5 \%$ [...] a senhora vê que as partes são assim decisivas, ciências da formação é sempre relativamente menor e o estudo do conteúdo da disciplina é relativamente maior, isto é a tradição [...]

O componente Ciências da Formação é mais valorizado na formação dos docentes para a escola primária do que nos demais níveis de ensino. Segundo B1m esses estudantes reconhecem a importância das disciplinas pedagógicas para a profissão. Existe entre eles a compreensão de que para a docência nos anos iniciais é mais importante enfatizar as atividades didático-pedagógicas do que propriamente aprender conteúdos das áreas de conhecimento (língua materna, matemática, ciências sociais e da natureza) ou das disciplinas ministradas (entre outras: música, artes, educação física e língua estrangeira), tendo em vista que os conteúdos introdutórios dessas 
áreas ou disciplinas já seria parcialmente conhecido pelos estudantes. ${ }^{10}$ Mesmo não sendo tão valorizado na formação de professores para os outros níveis escolares, B1m destaca que as Ciências da Formação adquiriram um espaço significativo na formação dos docentes de uma forma geral, com a inserção de fundamentos voltados às necessidades da formação das competências profissionais e não aos "hobbies científicos" dos professores universitários:

B1m: [...] é preciso dizer também que dentro da universidade, sim, como podemos descrever isso, é assim que ao longo dos últimos 10-20 anos essa parte das Ciências da Formação ganhou um pouco mais de visibilidade. Há 20 anos, há 40 anos muitos na universidade; também os professores, desprezavam essa parte diziam que não é ciência e assim por diante ou se teórico então não possui relevância para a prática. isso já melhorou um pouco eu posso dizer e as Ciências da Formação também se esforçaram para fazer isso por assim dizer de forma melhor, quando nós lá, quando nós olhamos pra trás e eu posso olhar muito, muito, muito longe pra trás ((risos)) isso era antes isso era realmente ruim, se fazia de tudo; mas deixemos a história isso faz muito tempo e agora as Ciências da Formação estão realmente melhores que há 20 anos ou 40 anos atrás; e isso vem do fato que nós agora prestamos mais atenção para que nos cursos de formação docente sejam oferecidas coisas [Dinge] que sejam relevantes para os futuros professores e não os nossos hobbies científicos por assim dizer; nós, isso precisa ser controlado, cada um tem que se engajar e sim isso funciona; claro que os professores têm a liberdade de lecionar mas eles precisam organizar suas coisas, os temas dos cursos e eles devem formular as coisas de modo que se adequem ao curso universitário aos módulos; alguns professores fazem isso sem reclamar outros nem tanto (risos).

Como já detalhado na primeira seção deste artigo, as Ciências da Formação constituem componente obrigatório na formação, articulando, principalmente, saberes das seguintes áreas: Ciências da Educação, Psicologia Escolar e do Desenvolvimento Humano, conhecimentos sociológicos sobre a escola e seus sujeitos, bem como conhecimentos filosóficos e políticos articulados a questões relevantes para os futuros docentes. Conhecimentos sobre processos de socialização e escolarização de crianças com histórico familiar de 
migração também constituem um eixo central em alguns módulos ministrados no componente Ciências da Formação.

O sentido da terminologia Bildungswissenschaften, entretanto, parece não ser consenso nos Institutos de Educação responsáveis por uma parte da formação docente. Segundo a entrevistada B2f:

B2f: [...] é também muito contestado assim o conceito de Bildung, também em função de todo o debate depois de 2000 no debate sobre Pisa no debate pós-Pisa foi novamente reforçado e trabalhou-se assim tanto o conceito de Bildung do ponto de vista teórico assim a partir da Ciência Geral da Educação como também as diferenças de todos os lados, também do ponto de vista da pesquisa empírica sobre formação assim no sentido quantitativo; trabalhou-se empiricamente com o conceito de Bildung incluindo também a Bildung não formal e não apenas a Bildung escolar e assim foi um debate muito interessante e em algum momento o conceito de Educação [Erziehung] ficou totalmente em segundo plano, poderíamos criticar isso e sempre volta a ser criticado e o conceito de Bildung se tornou uma espécie de termo contêiner e aí aconteceu isso que nós de um dia para o outro passamos a ser denominados como Ciências da Formação e os didáticos das disciplinas específicas pensam que nós de alguma forma temos posições parecidas às dos psicólogos, mas não é assim de forma alguma, nós temos claramente posições muito diferentes.

Com a junção das Ciências da Educação, da Psicologia e de outras disciplinas sob a terminologia Ciências da Formação, definida pela entrevistada como uma espécie de "contêiner", ocorreram diversos debates em torno do sentido atribuído ao conceito de Bildung nessa nova configuração que levou a um recuo da Erziehung e diminuição do peso que as Ciências da Educação (Erziehungswissenschaften) ocupavam até então na formação dos docentes. De acordo com B2f, os objetivos das Ciências da Formação ainda não são muito claros, parecendo distanciada do conceito clássico de Bildung, tendo em vista que o foco atual se concentra mais nos saberes voltados para a prática docente e não tanto na formação cultural mais ampla. Outro problema, segundo a entrevistada, é o fato de que visões distintas e até completamente contrárias em relação ao tratamento de questões como por exemplo a inclusão, não são claras para os professores das didáticas específicas e nem mesmo para os estudantes. As Ciências 
da Formação mantêm sob uma "cobertinha" distintas posições que podem ficar despercebidas para aqueles que não as conhecem, mas que dificultam o trabalho interdisciplinar, sobretudo entre cientistas da educação e psicólogos. O agrupamento das disciplinas não garantiu a articulação da formação, tendo em vista que os institutos e seus professores trabalham de forma independente. No entanto, a entrevistada considera que a terminologia Ciências da Formação já está instituída e não será mais alterada.

$\mathrm{Na}$ visão dos entrevistados de um dos ZLBs, o novo currículo gerou maior comprometimento dos professores universitários das outras áreas envolvidas na profissionalização dos docentes. Estes passaram a refletir e se preocupar mais com a formação dos docentes, intensificando as discussões sobre o papel desempenhado por eles na formação. Segundo o entrevistado Z1mI: "Então o que é preciso dizer, o que eu na perspectiva de professor universitário considero totalmente em ordem, é que pela primeira vez os colegas foram obrigados [a refletir] sobre o que eles de fato fazem e quanto eles querem fazer e [sobre] o quanto isso é importante e o quanto é trabalhoso; e isso foi uma coisa boa [...]".

Apesar dos pontos positivos da reforma, entre outros, o aumento da carga horária na formação dos docentes para a escola primária, a introdução de diversos estágios ao longo da formação e um maior comprometimento dos professores universitários com a formação dos docentes articulada com os ZLBs e com a rede de ensino, os entrevistados também destacaram alguns problemas com o novo currículo, por exemplo, em relação à organização da formação em bacharelado e mestrado. Segundo Z1mI, essa transição nem sempre ocorre de forma automática e articulada. Só com o bacharelado, os estudantes não podem trabalhar como docentes em escolas regulares, de forma que esse formato não faz tanto sentido para os cursos de formação docente. Outro aspecto apontado como negativo na divisão entre bacharelado e mestrado, diz respeito à mobilidade acadêmica que praticamente não ocorre entre estudantes dos cursos de formação para a docência, segundo Z2m:

Z2m: Eu não sou um especialista para isso mas eu já falei que os estudantes raramente vão para um outro lugar para fazer o mestrado; eu conheço os números mas são bem poucos assim que, sim essa era uma das vantagens prometidas, mas eles na realidade não tem nenhuma possibilidade de escolher um mestrado específico porque profissão docente é profissão 
docente $[. .$.$] nesse sentido nessas áreas eu acho que nós não$ precisaríamos eu acho que nós não precisaríamos, isso foi feito por causa de Lisboa e assim é bacharelado e mestrado.

Para estudantes dos cursos de formação para a docência a mobilidade acadêmica, por exemplo, mudança de universidade após o bacharelado, é complicada, uma vez que para o exercício da profissão docente o estudante precisa cursar o mestrado que dá sequência aos estudos iniciados no bacharelado. As possibilidades de contratação em um estado distinto daquele onde o estudante cursou o bacharelado e o mestrado também são mais difíceis, de forma que são praticamente forçados a realizar o mestrado na mesma universidade em que realizaram o bacharelado. Nesse sentido, a mobilidade estudantil prometida com o processo de Bolonha continua muito baixa para os estudantes dos cursos de formação docente. Ainda em relação a organização do curso em bacharelado e mestrado, os entrevistados dos dois ZLBs apontam uma tendência de "escolarização" da universidade, fruto da divisão entre bacharelado e mestrado e da organização dos cursos por módulos, bem como um excesso de regulamentação e burocratização da vida acadêmica:

Z2m: [...] e tornou-se claramente mais escolarizado por conta dos módulos o que nos incomoda sempre um pouco; os módulos são também pequenos reinados assim pegando essa imagem e eles pertencem a determinados grupos dentro de uma área e eles estabelecem dentro do quadro legal é claro mas também do que devem ser os conteúdos e as competências que devem ser transmitidas dentro do módulo e terminam com isso; mas se eu tomar Bolonha realmente a sério e quiser pôr em prática o desenvolvimento de competências eu não posso colocar aqui um módulo em prática e depois [fazer] algo and now to something completely different ${ }^{11}$ (risos) algo diferente e isso segue adiante; na realidade eu teria que ter um modelo de competência que eu possa operacionalizar nas diferentes fases do curso; mas isso não acontece, cada um tem o seu setor e o organiza e depois vem um outro setor [...] isso com certeza é até certo ponto um problema na modularização do curso ainda que tenha claramente aspectos positivos [...]

Os módulos deixaram os cursos mais parecidos com o formato escolar, com muitos conteúdos a serem trabalhados, pouca flexibilidade na grade curricular e autonomia dos estudantes na condução dos estudos. O estudo foi organizado no que Puntel 
(2002) chama de estrutura arqueológica, ou seja, programado desde o início, diferente do estudo da universidade do tipo humboldtiano em que o estudante tinha mais liberdade para organizar o seu currículo acadêmico. Os entrevistados também apontam um aumento de tarefas administrativas e burocráticas associadas à divisão entre bacharelado e mestrado e à organização de suas atividades dentro dos módulos. Além disso, existem, nos cursos, dúvidas em torno do cumprimento da formação das competências para o ensino por meio do formato de módulos, tendo em vista que a integração dos diferentes módulos nem sempre acontece. Observa-se a partir das falas citadas acima, que existem tensões e dificuldades de comunicação entre os responsáveis pelos diferentes módulos do componente Ciências da Formação bem como em outras áreas, o que de alguma forma incide sobre o objetivo de formar para as competências, tendo em vista que essas não dependeriam de módulos isolados, mas de uma reflexão teóricoprático articulada entre os quatro componentes que representam a base da formação dos futuros docentes.

\section{AUTONOMIA DAS UNIVERSIDADES E DESAFIOS NA ORGANIZAÇÃO DOS CURSOS APÓS BOLONHA}

A formação para a docência é determinada pelos Estados Federados, tendo em vista que estes são responsáveis pela estruturação da carreira. Desse modo, como já detalhado na primeira parte do artigo, os respectivos Estados da Alemanha definem as leis e diretrizes que orientam a organização dos cursos nas universidades. Quando questionado em relação aos aspectos que poderiam ser melhorados na formação do docente, o entrevistado Z1 mII respondeu o seguinte:

Z1mII: [...] assim tem uma quantidade e aí a questão é se podemos repensar ou se vai mudar e se acabam ficando as estruturas que já existem [...] quando pensamos de forma estrutural então podemos claramente fazer a pergunta precisamos um bacharelado e mestrado, esse é o caminho certo ou seria melhor ter outras regras, dez semestres com uma opção de saída já definida; mas todos esses são debates desenvolvidos numa esfera política que nós como universidade não conduzimos dessa forma; nós recebemos a legislação e a partir dela nós fazemos o melhor que nós podemos; claro que também nos perguntam quando há uma mudança na legislação, mas isso é algo que não é esperado; no momento nós nos concentramos na implementação daquilo que são nossas tarefas e sobretudo na organização dos conteúdos [...] 
Os professores podem debater a questão num nível político, mas não descumprem a legislação. Assim, mesmo considerando que a divisão entre bacharelado e mestrado não seja a mais adequada para os cursos de formação de docentes, as universidades buscaram se adaptar às novas regras e organizar os cursos da melhor forma possível. Trata-se de uma orientação legal que atua na universidade sem grandes resistências, tendo em vista a aposta nesse modelo para atender a demanda profissional e o fato de que o debate em torno da reforma é considerado como concluído e não faz mais parte da agenda de discussões.

Em relação às competências que se espera dos estudante $\mathrm{B} 1 \mathrm{~m}$ destaca o seguinte:

B1m: eu vou começar num plano geral //B1f: isso geral// e depois a escola primária; é assim que na esfera federal existem standards para a parte de Ciências da Formação, standards para competências que os Estados devem adaptar em seus contextos e isso e isso os Estados fizeram; os standards foram formulados de uma forma bem geral e os campos das competências são lecionar, educar, avaliar e aconselhar, inovar e formação continuada:

Apesar de algumas críticas, os cursos formam futuros docentes de acordo com as normas educacionais acordadas pela KMK e adaptadas pelo estado. Com base nas entrevistas realizadas, os cursos parecem ter realizado as adequações exigidas. A despeito do currículo dos cursos estar estruturado em torno das competências a serem adquiridas, a forma de ensino e a de avaliação por meio de exames ainda não corresponde a perspectiva que se propõe ir além do ensino e da verificação dos conteúdos aprendidos. Segundo o entrevistado $\mathrm{B} 1 \mathrm{~m}$, esse problema persiste há algumas décadas e está relacionado à tendência de a universidade avaliar o domínio de conteúdos ao invés das "capacidades práticas" dos futuros docentes. As habilidades docentes são levadas em consideração somente durante a residência pelos responsáveis por essa etapa de avaliação, ou seja, pelo docente que acompanha o residente e pelos supervisores dos Ministérios de Educação de cada Estado designados para essa função.

Os Estados, em acordo com a KMK, estabelecem as áreas de aprendizagem, as competências a serem alcançadas, o número de créditos dos cursos. No entanto, mesmo reconhecendo a necessidade de seguir os padrões estabelecidos para a formação docente, os entrevistados foram praticamente unânimes em afirmar que possuem autonomia no desenvolvimento das atividades acadêmicas. 
Ef: [...] Nós gostaríamos de saber ainda assim algo sobre a autonomia da universidade na organização do curso ou os senhores acham que agora é muito dominado pela $L A B G$ ou tem ainda espaço que a universidade diga ok; tem a lei mas nós podemos organizar o curso de modo que cada universidade tenha o seu perfil.

Z1mI: Bem eu posso avaliar apenas na minha área assim as possibilidades de ação ainda são muitas [...] assim nós temos as diretrizes que incomodam extremamente, nós temos que atribuir pontuação para o rendimento [Leistungspunkte] e isso chega próximo ao nível do absurdo; mas digamos que quando se está disposto a seguir isso e a lidar de forma criativa podese fazer então de fato muitas coisas com isso.

Z1mII: Eu reforço isso, tem muitas diretrizes formais mas poucas diretrizes sobre conteúdos; nisso o Estado é absolutamente cauteloso porque nós temos por princípio de liberdade de ensino e pesquisa e nisso não se procura mexer muito [...] por exemplo em relação à disciplina de matemática ou alemão e de forma concreta em relação ao que é feito nos conteúdos isso são os professores e professoras que decidem [...]

A LABG define as normas e a estrutura do bacharelado e do mestrado, mas cada universidade pode desenvolver um currículo próprio para o curso e os professores têm liberdade em relação à organização dos conteúdos e programas dos cursos de leitura (Vorlesungen) e seminários ministrados. Os módulos dos cursos são pensados pelos professores que estão nas respectivas faculdades ou institutos e por isso são distintos de uma universidade para outra como apontado na primeira parte do artigo. O entrevistado $\mathrm{Z} 2 \mathrm{~m}$ também confirma a existência da autonomia universitária, destacando a pesquisa acadêmica e a forma de contratação de professores:

Ef: [...] como o senhor avalia as possibilidades de ação ou melhor da autonomia da universidade na organização dos planos de estudos e do currículo quando se tem a LABG e Bolonha como base; a universidade ainda tem autonomia para trabalhar o currículo ou já está muito preestabelecido?

Z2m: Sim nós também temos autonomia para trabalhar o currículo [...] quando a senhora pergunta às pessoas que não trabalham diretamente com a formação de docentes aqui na universidade eles acham tudo muito ruim esses limites; 
porque num curso normal eu posso fazer o que eu quero lá não tem um Ministério, aqui tem um parâmetro legislativo no qual eu me movo que demarca essas competências [...] elas são definidas de forma bem ampla mas estão definidas, bem ampla mas definidas e dentro dessa definição ampla [...] nós também podemos constituir os nossos focos e assim nós nos diferenciamos da Universidade- $X$ ou Universidade- $Y$; nós somos a universidade da heterogeneidade esse é um foco além disso vem naturalmente a linha de pesquisa dos professores das Ciências não apenas das Ciências da Formação também dos que trabalham na Pesquisa Escolar e nas Ciências da Formação [...] nós somos um grande local de pesquisa por assim dizer da pesquisa sobre formação de professores; muitos, muitos recursos financeiros principalmente na área de Ciências da Natureza que depois trabalha junto com as Ciências da Formação em diferentes questões [...] e isso o Ministério não pode prescrever como a didática deverá funcionar depois de amanhã, nós é que pesquisamos [...] um outro pilar da autonomia da nossa pesquisa é o contrato // Ef: sim // nossa forma de contratação, quem nós contratamos quem nós queremos [...] que tipo de perfil as pessoas têm, o que nós queremos [...]

O desenvolvimento do currículo, a definição de focos de interesse e de diferenciação entre universidades bem como a pesquisa acadêmica não é algo decidido pelos Ministérios. O que se pesquisa e como se pesquisa também influencia a organização dos módulos dos cursos de formação. Os concursos para as cátedras ocupadas pelos professores é realizada pela própria universidade, não pelo Estado. Desse modo, os cursos possuem autonomia para decidir o perfil das cátedras e dos focos de pesquisa nas respectivas áreas, considerando, no entanto, as exigências em relação às competências profissionais dos futuros docentes.

De uma forma geral, podemos afirmar que os cursos são direcionados pelos Estados no que diz respeito às questões centrais da formação, no entanto, sem que as universidades tenham que abrir mão de sua autonomia no que se refere às suas particularidades contextuais e temas de pesquisa. Apesar de algumas dificuldades, os cursos de formação de docentes para a escola primária procuram atender da melhor forma possível as normas acordadas pela KMK e implementados através da LABG e do LZV, formando o docente 
com as competências estabelecidas. Em outras palavras: os Estados determinam a estrutura básica da formação nas universidades, mas não impedem a realização de uma formação para além das necessidades da profissão docente. Entretanto, diante da grande quantidade de créditos obrigatórios, das diversas competências exigidas, da enorme quantidade de estudantes nos cursos, obviamente, há pouco espaço na grade curricular para atividades voltadas a outros interesses, como por exemplo, de renovação do saber cultural, da integração social, de geração de solidariedade, o que permitiria não apenas a interação com as necessidade da economia e da administração, mas também com as funções de reprodução do mundo da vida.

\section{CONSIDERACְ̃̃ES FINAIS}

A partir da pesquisa realizada observamos que os projetos pedagógicos das universidades Duisburg-Essen e Münster se alicerçam nas orientações profissionalizantes dos documentos da KMK, da LABG e da LVZ. O foco é preparar o futuro docente com as competências necessárias para o trabalho na escola primária. Tais propósitos orientadores, apesar de críticas recebidas, foram incorporados nos currículos dos cursos com o objetivo de formar profissionais crítico-reflexivos que correspondam às demandas do sistema educacional. Os cursos demonstram, claramente, os seus alicerces na profissionalização da área de ensino para a educação básica, tendo em vista a vinculação da universidade aos Estados Federativos e a adesão à proposta de uma base comum de formação elaborada no âmbito da KMK (Kultusministerkonferenz). Com esse compromisso, as universidades parecem focar no atendimento da formação para a aquisição das competências para o ensino, deixando a formação científica e cultural mais ampliada a critério dos estudantes que, embora não sejam incentivados, não estão impedidos de frequentar outras disciplinas e atividades artísticas ou de pesquisa que não fazem parte da grade curricular obrigatória do seu próprio curso.

Os entrevistados apontam elementos positivos decorrentes da reforma, mas também problemas que têm prejudicado o andamento dos cursos. Apesar de afirmarem que os cursos funcionam bem diante das demandas da escola, percebemos um certo descontentamento e dificuldades em relação a nova estrutura por parte de alguns entrevistados, principalmente, no que se refere a escolarização dos cursos. O único acordo parece ser em torno do objetivo de permitir 
o desenvolvimento das competências profissionais exigidas para o magistério, pois não encontramos resistência em torno desse propósito. As críticas apontadas referem-se mais aos desafios em relação à formação por competências profissionais, mas não no que se refere à proposta. $\mathrm{O}$ que nos parece é que os cursos são obrigados a seguir as determinações do estado da NRW, já que é este o financiador da universidade e regulador do exame de estado que autoriza o exercício do magistério.

As competências são entendidas nos cursos enquanto dependência da teoria e da prática, jamais desvinculada do conhecimento, pois são muitos os estudos teóricos, apesar desses estudos serem quase todos voltados às necessidades do campo profissional prático. Atendendo às exigências da legislação, os cursos oferecem um espaço relevante para as áreas de conhecimento ou disciplinas escolhidas pelos estudantes, para as didáticas das disciplinas específicas, práticas de ensino e para as Ciências da Formação. Percebemos, na descrição dos módulos do componente Ciências da Formação, que discussões da sociologia da educação e da filosofia da educação aparecem de forma mais enfraquecida, dissolvidas nos diferentes módulos. As orientações sobre questões sociais são colocadas no sentido de permitir o desenvolvimento de uma competência para a socialização e solução de conflitos. A formação do sujeito crítico se destaca com ênfase na crítica analítica da própria prática, das teorias científicas e das implicações políticas da formação, não como crítica social, do sistema educacional ou do mundo da vida. Estudos para uma formação mais ampliada, voltados para as necessidades da vida humana acabam sem muito espaço. A pesquisa científica também é reduzida a reflexão sobre a prática, ficando na incumbência, praticamente, dos professores. Isso é positivo no sentido de que os estudantes, ainda muito jovens, são orientados para a profissionalização e desenvolvimento da identidade docente. Mas também negativo porque simplifica a tarefa da formação docente na universidade no atendimento das exigências referentes às necessidades mais imediatas de adaptação ao mundo sistêmico.

Nota-se que a pesquisa foi postergada e negligenciada em favor do ensino e em grande parte sufocada por uma atmosfera dominada por fatores frequentemente alheios à ciência (PUNTEL, 2002). Apesar de buscarem garantir a ideia humboldtiana de unidade do ensino e da pesquisa, o que observamos foi uma ênfase na profissionalização em detrimento da formação intelectual e humanística. Considerando a democratização do acesso à universidade, não defendemos que os 
cursos tenham que oportunizar a Bildung no sentido de Humboldt, o que seria atualmente impossível, mas talvez repensar o sentido da formação universitária de modo a articular a formação profissional com a formação humanística. A nosso ver, isso traria consequências positivas para a docência na educação básica, tendo em vista que a prática docente aconteceria não apenas com o enfoque no mercado de trabalho, o que é extremamente importante, mas permitiria também uma formação mais autônoma e humanizada para os estudantes.

\section{REFERÊNCIAS}

ASBRAND, B.; HELLER, N.; ZEITLER, S.. Die Einführung von Bildungsstandards in das deutsche Bildungssystem. In: ZEITLER, S.; HELLER, N.; ASBRAND, B. Bildungsstandards in der Schule. Eine rekonstruktive Studie zur Implementation der Bildungsstandards. Münster et al:: Waxmann, p. 11-21, 2012.

BLÖMEKE, S. Globalization and educational reform in German teacher education. International Journal of Educational Research. Amsterdam et al, v. 45, n. 4, p. 315-324, 2006.

CASALE, R., RÖHNER, C., SCHAARSCHUCH, A., SÜNKER, H. Entkopplung von Lehrerbildung und Erziehungswissenschaft: von der Erziehungswissenschaft zur Bildungswissenschaft. Erziehungswissenschaft. Leverkusen et al., v. 21, n. 41, p. 43-66., 2010.

DÖBERT, H. Germany. In: HÖRNER, W., DÖBERT, H., REUTER, L.R., von KOPP, B. (ed.). The Education Systems of Europe. Second Edition. Cham (Switzerland) et al:: Springer, p. 305-333, 2015.

HILLIGUS, A. H. Structural features and particularities of initial teacher education in germany: the specific role of universities. In: KUHLEE, D.; VAN BUER, J.; WINCH, C. (org.) Governance in initial teacher education: perspectives on England and Germany. Wiesbaden, Springer VS, p. 113-130.

KMK-Kultusministerkonferenz.StandardsfürdieLehrerbildung:Bildungswissenschaften. Beschluss der Kultusministerkonferenz vom 16.12.2004. Disponível em:<https://www. $\mathrm{kmk}$.org/fileadmin/Dateien/veroeffentlichungen_beschluesse/2004/2004_12_16Standards-Lehrerbildung.pdf> . Acesso : 17 abr. 2017.

KMK - Kultusministerkonferenz. Ländergemeinsame inhaltliche Anforderungen für die Fachwissenschaften und Fachdidaktiken in der Lehrerbildung Deutschland (Beschluss der Kultusministerkonferenz vom 16.10.2008 i. d. F. vom 16.03.2017). Disponível em: $\leq$ http://www.kmk.org/fileadmin/Dateien/veroeffentlichungen_ beschluesse/2008/2008_10_16-Fachprofile-Lehrerbildung.pdf $\geq$. Acesso em: 17 jun. 2017.

KOTTHOFF, H.-G. Between excellence and equity: the case of the German education system. Revista Española de Educación Comparada, Madrid, n. 18, p. 27-60, 2011.

NRW - NORDRHEIN-WESTFALEN. Ministerium für Schule und Weiterbildung des Landes Nordrhein-Westfalen. Lehramtszugangsverordnung - LZV (Vom 25. April 
2016). Disponível em: $\leq$ https://recht.nrw.de/lmi/owa/br_vbl_detail_text?anw_nr=6\&vd_ $\mathrm{id}=15620 \& v e r=8 \& v a l=15620 \& s g=0 \& \mathrm{menu}=1 \& v d \_b a c k=\mathrm{N}>$. Acesso em: 17 abr. 2017.

NRW - NORDRHEIN-WESTFALEN. Ministerium fürSchule... Lehrerausbildungsgesetz - LABG (Vom 12. Mai 2009 zuletzt geändert durch Gesetz vom 14. Juni 2016). Disponível em: Shttps://www.schulministerium.nrw.de/docs/Recht/LAusbildung/LABG/ LABGNeu.pdf> Acesso em: 17 jun. 2017.

MERKENS, H. (org.). Lehrerbildung: Zentren für Lehrerbildung. Wiesbaden: VS Verlag für Sozialwissenschaften, 2005.

PARLAMENTO EUROPEU; CONSELHO DA UNIÃO EUROPEIA. Recomendações do parlamento europeu e do conselho. 18 de Dezembro de 2006. Disponível em: < http:/ / eur-lex.europa.eu/legal-content/PT/TXT/?uri=celex:32006H0962>. Acesso em: 17 abr. 2017.

PUNTEL, L. B. A universidade alemã: tradição, situação crítica atual, perspectivas. In: ROHDEN, V. Ideias de Universidade. Canoas: Ed. Ulbra, 2002.

RADTKE, F.-O. Konditionierte Strukturverbesserung. Umbau und Neuformierung der deutschen Erziehungswissenschaft flankiert von der Deutschen Forschungsgemeinschaft unter Anleitung der OECD verwirklicht von der Kultusministerkonferenz. Zeitschrift für Pädagogik. Weinheim, v. 62, n. 5, p. 707-731, 2016.

STEINER-KHAMSI, G.(org.). The Global Politics of Educational Borrowing and Lending. New York: Teachers College Press, 2004.

TERHART, E. Standards für die Lehrerbildung ein Kommentar. Zeitschrift für Pädagogik. Weinheim, v. 51, n. 2, p. 275-279, 2005.

TERHART, E. Vom pädagogischen Begleitstudium zu den Bildungswissenschaften in der Lehrerinnen- und Lehrerbildung: Themen und Trends. Beiträge zur Lehrerbildung. Langnau, Emmental: SGL, v. 30, n. 1, p. 49-61, 2012.

TERHART, E. Standards für die Lehrerbildung: Bildungswissenschaften nach zehn Jahren. Die Deutsche Schule. Münster et al., v. 106, n. 4, p. 300, 2014.

UDE - UNIVERSITÄT DUISBURG-ESSEN. Modulhandbuch Bachelor. Lehramt an Grundschulen. (2016/2017). Disponível em: ,<https://www.uni-due.de/studienangebote/ studiengang.php?id=157>. Acesso em: 17 abr. 2017.

UDE - UNIVERSITÄT DUISBURG-ESSEN. Modulhandbuch Master. Lehramt an Grundschulen. (2015/2016). Disponível em: <https://www.uni-due.de/studienangebote/ studiengang.php?id=134>. Acesso em: 17 abr. 2017.

WELLER, W.; ZARDO, S. Entrevista narrativa com especialistas: aportes metodológicos e exemplificação. Revista da FAEEBA- Educação e Contemporaneidade, Salvador, v. 22, n. 40, p. 131-143, jul/dez, 2013.

WWU - WESTFÄLISCHEN WILHELMS-UNIVERSITÄT MÜNSTER. Ordnung für die Prüfungen des bildungswissenschaftlichen Studiums zur Rahmenordnung für die Bachelorprüfungen an der Westfälischen Wilhelms-Universität Münster innerhalb des Studiums für das Lehramt an Grundschulen. Munster, 2011. Diposnível 
em: <http://www.unimuenster.de/imperia/md/content/bildungswissenschaften/ ordnungen/3._o_ba_g_ab.pdf $>$. Acesso em: 17 abr. 2017.

WWU - WESTFÄLISCHEN WILHELMS-UNIVERSITÄT MÜNSTER. Erste Ordnung zur Änderung der Ordnung für die Prüfungen des bildungswissenschaftlichen Studiums zur Rahmenordnung für die Prüfungen im Studium für das Lehramt an Grundschulen mit dem Abschluss. Master of Education. Munster, 2015. Disponível em: <http://www.unimuenster.de/imperia/md/content/bildungswissenschaften/ ordnungen/_o_med_g.pdf.> Acesso em: 17 abr. 2017.

\section{NOTAS}

${ }^{1}$ Fonte: Recomendação do Parlamento e do Conselho Europeu de 18 de dezembro de 2006. Disponível em: <http://eur-lex.europa.eu/legal-content/PT/TXT/ PDF/?uri=CELEX:32006H0962\&from=PT>. Acesso em: 10 jul. 2017.

${ }^{2}$ Para maiores informações sobre a KMK cf. https://www.kmk.org/kmk/information-inenglish.html. Acesso em: 17 jul. 2017.

${ }^{3}$ Para maiores detalhes sobre a organização do sistema educacional alemão, cf. Hilligus, 2015; Döbert, 2015.

${ }^{4}$ Este componente curricular será detalhado na seção seguinte deste artigo.

${ }^{5} \mathrm{LP}=$ Leistungspunkte (equivalente a créditos).

${ }^{6}$ As informações foram obtidas a partir da leitura das ementas constantes nos documentos pesquisados na WWU e UDE.

${ }^{7}$ Como mencionado anteriormente, enquanto na WWU esse estudo está sob responsabilidade do Instituto de Sociologia, na UDE é ministrado por professores do Instituto de Ciências da Educação.

${ }^{8}$ Para maiores informações sobre os ZLBs, cf. Merkens, 2005; Hilligus, 2015.

${ }^{9}$ Contudo, existe ainda uma diferença salarial do docente dos anos iniciais em relação aos demais níveis de ensino

${ }^{10}$ Os estudantes que optaram pela docência na escola primária também podem escrever o trabalho final de curso, tanto do bacharelado como do mestrado, na área de Ciências da Formação.

${ }^{11}$ Tradução da expressão utilizada em inglês: "E agora para algo completamente diferente". A expressão remete ao título de um filme inspirado na série de televisão Monty Python's Flying Circus.

Submetido: $27 / 02 / 2018$

Aprovado: $11 / 05 / 2018$

Contato:

Universidade de Brasília - UnB Faculdade de Educação Campus Universitário Darcy Ribeiro 